\title{
Influenza: datos de interés
}

\author{
Influenza: interesting data \\ Enrique Gutiérrez,* Iván Felipe Gutiérrez, ${ }^{\ddagger}$ José Alejandro Mojica, ${ }^{\S}$ Cristina Mariño, ${ }^{\|}$Pío López ${ }^{\Uparrow}$ \\ * Profesor Emérito, Hospital Militar. Bogotá, Colombia. \\ ₹ Infectólogo Pediatra, Clínica Colsanitas. Bogotá, Colombia. \\ $\S$ Infectólogo Pediatra, Ministerio de Salud y Protección Social. \\ " Infectóloga Pediatra, Coordinadora de Infectología Pediátrica, Hospital Militar. Bogotá, Colombia. \\ "Infectólogo Pediatra, Hospital Universitario Del Valle, Centro de Estudios en Infectología Pediátrica. Cali, Colombia.
}

RESUMEN

La influenza es una enfermedad de etiología viral que se manifiesta principalmente con una sintomatología con compromiso del tracto respiratorio, y que puede variar de leve a moderada a grave y llegar a ser una causa importante de morbilidad y mortalidad dependiendo de los grupos de edad afectados (es más grave en los extremos de la vida, menores de cinco años y mayores de 60), y en aquéllos con comorbilidades previas (diabetes, obesidad, enfermedades respiratorias o cardiovasculares crónicas y otras). En 2009, la cepa $A(H 1 N 1)$ alcanzó proporciones pandémicas con una mortalidad entre 100,000 a 400,000 sujetos. La primera pandemia del siglo XXI. Este virus, designado hoy como el $A(\mathrm{H} 1 \mathrm{~N} 1)$ pdm09, gradualmente pasó a convertirse en un virus estacional a partir de 2010, y como tal continúa circulando en forma endémica hasta la fecha en los países de América Latina. Es fundamental la vigilancia de la circulación de los virus de influenza, tanto en el ámbito global como en el nacional. En el mundo, más de 120 países tienen un Centro Nacional de Influenza encargado de la vigilancia de la circulación de los virus. Se revisa la epidemiología global y regional desde América del Norte, Central y Suramérica en países seleccionados y se revisan las opciones de tratamiento y las vacunas disponibles. Igualmente, las recomendaciones de la Organización Mundial de la Salud (OMS). Se revisan las políticas de los países con respecto a sus estadísticas, políticas de vacunación y a sus recursos financieros.

Palabras clave: Influenza, epidemiología, clínica, vacunación, América Latina, Norteamérica, antivirales, vacunas tetravalentes, financiamiento.

\section{ABSTRACT}

Influenza is a disease of viral etiology that mainly manifests itself with a symptomatology involving the respiratory tract and can vary from mild to moderate to severe and become a major cause of morbidity and mortality depending on the age groups affected,(It is more severe in the extremes of life, under 5 years and over 60) and in those with previous comorbidities (diabetes, obesity, chronic respiratory or cardiovascular diseases and others). In 2009, the A(H1N1) strain reached pandemic proportions with mortality between 100,000 and 400,000 subjects. The first pandemic of the 21 st century. This virus, designated today as $A(H 1 N 1)$ pdm09, gradually became a seasonal virus as of 2010, and as such continues to circulate endemically to date in Latin American countries. Surveillance of influenza virus circulation is essential, both globally and at the country level. Worldwide, more than 120 countries have a National Influenza Centre responsible for surveillance of virus circulation. Global and regional epidemiology from North, Central and South America in selected countries is reviewed and treatment options and available vaccines are reviewed. Also, the recommendations of the World Health Organization (WHO). Country policies are reviewed with respect to their statistics, vaccination policies, and financial resources.

Keywords: Influenza, epidemiology, clinical, vaccination, Latin America, North America, antivirals, tetravalent vaccines, financing.
Financiamiento: Ninguno.

Conflicto de intereses: Ninguno.

https://dx.doi.org/10.35366/92382

Rev Latin Infect Pediatr 2020; 33 (1): 19-27

\section{EPIDEMIOLOGÍA NACIONAL, REGIONAL Y GLOBAL}

Tanto los virus A como los B son causa de brotes estacionales, en ocasiones verdaderamente epidémicos (como el de la estación 2017-18 en los Estados Unidos).

En forma global, la influenza tiene una tasa de ataque que se estima entre $5-10 \%$ en los adultos y entre $20-30 \%$ en los niños. 
En los climas templados (hemisferios Norte y Sur), los brotes se presentan durante los meses de invierno, cuando se inicia la circulación de los virus, mientras que, en los climas tropicales, los virus circulan durante todo el año con mayor o menor intensidad y la enfermedad se presenta en brotes en cualquier momento con alguna irregularidad, predominando en las temporadas de lluvia.

Los virus de influenza A también pueden causar pandemias caracterizadas por una rápida diseminación de un nuevo subtipo de A, que tenga la capacidad de transmisión de humano a humano en forma sostenida y eficiente.

En el siglo pasado, se presentaron tres pandemias (1918, 1957 y 1968), denominadas respectivamente «Influenza Española», la más devastadora de todas, que coincidió con el final de la I Guerra Mundial y se estima que causó entre 20 y 100 millones de muertes, seguida de la influenza Asiática con uno a dos millones de muertes y la influenza de Hong Kong, que causó cerca de un millón de muertes..$^{1,2}$

En 2009, la cepa $A(\mathrm{H} 1 \mathrm{~N} 1)$ alcanzó proporciones pandémicas con una mortalidad entre 100,000 a 400,000 sujetos. La primera pandemia del siglo XXI. Este virus, designado hoy como el $\mathrm{A}(\mathrm{H} 1 \mathrm{~N} 1)$ pdm09, gradualmente pasó a convertirse en un virus estacional a partir de 2010, y como tal continúa circulando hasta la fecha.

Es fundamental la vigilancia de la circulación de los virus de influenza, tanto en el ámbito mundial como nacional. En el mundo, más de 120 países tienen un Centro Nacional de Influenza encargado de la vigilancia de la circulación de los virus.

Los datos recogidos son enviados a cinco centros de referencia localizados en Australia (Melbourne), Japón (Tokio), China (Beijín), Reino Unido (Londres) y EEUU (Atlanta).

Estos centros analizan las muestras recibidas de los países y envían los resultados de esa vigilancia a la OMS en Ginebra, donde se seleccionan los virus que circularán con mayor probabilidad en la siguiente temporada y envían su recomendación a las casas productoras de vacunas para su elaboración.

\section{EPIDEMIOLOGÍA REGIONAL}

\section{América del Norte}

En la semana epidemiológica (SE) 1 del 2020, la actividad de influenza continúo elevada en la subregión. En Canadá el virus influenza B circula a niveles más altos de lo habitual con la circulación concurrente de los virus influenza $A(\mathrm{H} 3 \mathrm{~N} 2)$ y $\mathrm{A}(\mathrm{H} 1 \mathrm{~N} 1)$ pdm09, mientras que en los Estados Unidos predominaron los virus Influenza B/Victoria asociados con una mayor actividad de ETI con circulación además de los virus influenza $A(\mathrm{H} 1 \mathrm{~N} 1)$ pdm09 e influenza $\mathrm{A}(\mathrm{H} 3 \mathrm{~N} 2)$. La tasa más alta de hospitalización fue entre los adultos mayores de 65 años (33.3 por 100,000 habitantes) seguidos de niños de cero a cuatro años (26.8 por $1,000,000$ habitantes). En la SE 1 del 2020, 5.8\% de las muertes reportadas se debieron a neumonía e influenza; este porcentaje está por debajo del umbral epidémico que se encontró en la SE 52 que fue de $6.9 \%$. La actividad de influenza presentó una actividad decreciente en la subregión y los casos de IRAG entre todas las hospitalizaciones estuvieron en niveles bajos comparados con épocas pasadas.

\section{América Central}

\section{México}

Los virus de la influenza $A(H 3 N 2)$ e influenza $A(H 1 N 1)$ pdm09 circularon concurrentemente. En la semana 1 del 2020 las detecciones de influenza disminuyeron mínimamente en comparación con la semana anterior, con la circulación concurrente de los virus influenza $A(H 3 N 2)$ e influenza $A(H 1 N 1)$ pdm09. Las detecciones de VRS disminuyeron en comparación con la semana anterior, con pocas detecciones de este virus reportadas. Hasta la semana 1 se notificaron 1,212 casos acumulados de IRAG/ETI.

\section{Costa Rica}

En la semana 1 del 2020, el porcentaje de positividad de influenza disminuyó en comparación con la semana anterior, con la circulación concurrente de los virus de la influenza $B$ y $A(H 3 N 2)$. La actividad VRS disminuyó en las últimas semanas con la circulación conjunta de rinovirus y coronavirus. El número de casos de IRAG continuó disminuyendo y se ubicó en niveles ínterestacionales.

\section{Panamá}

La actividad de influenza se mantiene en niveles interestaciónales en Panamá. Durante la SE 1 de 2020 , a nivel nacional, se informaron escasas detecciones de influenza con la circulación de los virus influenza B/Victoria. El porcentaje de positividad 
del VRS aumentó ligeramente en comparación con la semana anterior y estuvo dentro de los niveles observados en temporadas anteriores con pocas detecciones reportadas esta semana con la circulación concurrente de rinovirus.

\section{Suramérica}

\section{Colombia}

Después de un segundo pico en la SE 49 de 2019, la actividad de la influenza disminuyó, con la circulación concurrente de los virus influenza $A(\mathrm{H} 1 \mathrm{~N} 1)$ pdm09 e influenza B durante la SE 1 de 2020. Se informaron detecciones de VRS con la circulación conjunta de parainfluenza y adenovirus. En la SE 1, la transmisibilidad de la influenza representada por la combinación de los casos de IRA y el porcentaje de positividad de la influenza se mantuvo en niveles bajos de intensidad por encima de la curva promedio. A lo largo de la temporada 2019 , el recuento de los casos de IRAG, las hospitalizaciones relacionadas con la neumonía y el número de casos de IRA continuaron por debajo de los niveles estacionales.

Mirando la carga de la enfermedad y los grupos de edad con mayor proporción de casos de consulta externa y urgencias por infección respiratoria aguda (IRA), encontramos que $31.6 \%$ corresponde a menores de cinco años, seguido por el grupo de 20 a 39 años con $22.2 \%$.

Los casos de infección respiratoria aguda grave (IRAG), se presentaron en $44 \%$ en menores de un año y la mortalidad por IRA fue de $67.2 \%$ en el mismo grupo de edad, $21 \%$ entre el año y los dos años y $11.8 \%$ en el grupo de dos a cuatro años.

En cuanto a las hospitalizaciones en la sala general por IRAG por grupos de edad, $54.3 \%$ fue en menores de cinco años, seguido del grupo de mayores de 60 años con $20.5 \%$.

Estos son los grupos que deben ser priorizados para la vacunación contra la influenza, sin embargo, los datos nos muestran una realidad lamentable. EI porcentaje de vacunación contra la influenza en los casos de IRAG inusitado durante el 2018 nos dice que $58.42 \%$ no había recibido la vacuna, y solamente $5.68 \%$ sí la habían recibido.

\section{Ecuador}

En la SE 1 de 2020, las detecciones de influenza aumentaron en comparación con la semana previa, con la predominancia del virus influenza $A(\mathrm{H} 1 \mathrm{~N} 1)$ pdm09 y la circulación concurrente de influenza A(H3N2). El porcentaje de positividad aumentó ligeramente sobre la curva epidémica promedio para la SE 52. Se reportaron pocas detecciones de VRS esta semana.

\section{Perú}

En la SE 1, las detecciones de influenza disminuyeron en comparación con la semana anterior con la circulación de los virus influenza B/Victoria. El porcentaje de positividad de influenza permaneció en niveles similares de la semana previa y continuó por debajo de la curva epidémica promedio. No se informaron detecciones de VRS. Desde la SE 42 de 2019, el recuento de casos de IRAG presentó una tendencia decreciente por debajo del umbral estacional.

\section{Brasil}

En la SE 52, no se informaron detecciones de influenza, con circulación concurrente de influenza $A(H 1 N 1) p d m 09$ y $B$ en semanas previas; el porcentaje de positividad de influenza disminuyó en comparación con la semana anterior y estuvo en un nivel de actividad moderado. No se informaron detecciones de VRS. El número de casos de IRAG disminuyó y estuvo en niveles interestacionales. El número de casos de ETI disminuyó esta semana y estuvo dentro de los niveles observados durante las temporadas 2016-2018 para el mismo periodo. ${ }^{3,4}$

\section{CLÍNICA DE LA ENFERMEDAD}

Cefalea, fiebre $\geq 38{ }^{\circ} \mathrm{C}$, tos, dolor de garganta, congestión nasal, mialgias, artralgias, hipoxemia, hipotensión, neumonía, compromiso del SNC, muerte.

Influyen en la gravedad de la enfermedad factores del hospedero y factores del virus.

\section{Factores del hospedero}

Individuos con alto riesgo y mayor susceptibilidad a enfermedad grave:

Adultos $>65$ años, lactantes $<2$ años, embarazadas e inmunocomprometidos.

Condiciones de salud subyacentes que incrementan susceptibilidad: asma, EPOC, enfermedades cardiovasculares, desórdenes neurológicos, 
obesidad, diabetes, otros: respuesta inflamatoria exacerbada y sostenida.

Variantes polimórficas de genes involucrados en la respuesta inmune. SNP rs361525, SNP rs11252 en factor IFITM3, otros.

Factores virales. Proteínas virales mediadores de la infección. HA y NA que determinan antigenicidad, tropismo. PB1, PB2, PA y NP, determinan competencia replicativa, genotipo de NA y M2 determina resistencia a antivirales.

\section{Definición de caso}

Sujeto con inicio súbito de fiebre $>38^{\circ} \mathrm{C}$ con tos y dolor de garganta en ausencia de otros diagnósticos.

Criterios de laboratorio: aislamiento del virus: escobillón o aspirado del individuo sospechoso o detección directa del antígeno $(\mathrm{Ag})$ viral de influenza. Amplificación de ÁcidosVa nucleicos (PCR).

Serología: Aumento de cuatro veces en el título de Ac en suero agudo y convaleciente.

\section{Clasificación de caso}

Sospechoso: un caso que cumple con la definición clínica de caso.

Confirmado: además de lo anterior, es confirmado por laboratorio. ${ }^{5}$

\section{VACUNACIÓN}

La mejor manera de controlar la influenza es a través de la vacunación. Si esta se realiza en los establecimientos educativos en la población escolar, es mucho más efectiva.

En las políticas de inmunización siempre hubo prioridad de vacunar contra la influenza a los mayores de 65 años entre otros. Para el Dr. Parker Smith, promotor a cargo del programa "Control Flu», este esfuerzo debe dirigirse especialmente a la inmunización de niños.

Pudieron comprobar que cuando en una comunidad $20 \%$ de los niños de cinco a 18 años es inmunizado, resulta más efectivo que $90 \%$ de los adultos vacunados.

\section{POBLACIONES CON MAYOR RIESGO \\ DE COMPLICACIONES MÉDICAS ATRIBUIBLES A LA INFLUENZA SEVERA}

Todas las personas de edad $\geq 6$ meses que no tienen contraindicaciones deben vacunarse anual- mente. Sin embargo, la vacunación para prevenir la influenza es particularmente importante para las personas que tienen un mayor riesgo de enfermedades graves. Cuando el suministro de vacunas es limitado, los esfuerzos de vacunación deben centrarse en administrar la vacuna a las personas con mayor riesgo de complicaciones médicas atribuibles a la influenza grave que no tienen contraindicaciones. Estas personas incluyen (el orden de inclusión no implica jerarquía):

- Todos los niños de seis a 59 meses.

- Todas las personas de edad $\geq 50$ años.

- Adultos y niños que tienen trastornos pulmonares crónicos (incluido el asma), cardiovasculares (excluida la hipertensión aislada), renales, hepáticos, neurológicos, hematológicos o metabólicos (incluida la diabetes mellitus).

- Las personas que están inmunocomprometidas por cualquier causa (incluidas, entre otras, la inmunosupresión causada por medicamentos o infección por VIH).

- Mujeres que están o estarán embarazadas durante la temporada de influenza.

- Niños y adolescentes (de seis meses a 18 años) que reciben medicamentos que contienen aspirina o salicilato y que podrían estar en riesgo de experimentar el síndrome de Reye después de la infección por el virus de la influenza.

- Residentes de hogares de ancianos y otros centros de atención a largo plazo.

- Indios americanos/nativos de Alaska.

- Personas extremadamente obesas (índice de masa corporal $\geq 40$ para adultos).

- La inmunidad vacunal se atenúa con el tiempo.

- Las más utilizadas en el mundo son vacunas inyectables de virus inactivados. Las vacunas son más eficaces y efectivas a mayor coincidencia entre virus circulantes y virus vacunales.

- La OMS actualiza la composición de las vacunas dos veces al año.

- Una Recomendación para el Hemisferio Norte que se hace en febrero y una para el Hemisferio Sur que se hace en septiembre.

- Tipos de Vacunas: virus inactivados (vacunas trivalentes y tetravalentes) vacunas recombinantes y vacunas con virus atenuados (aerosol nasal)

- Las vacunas Trivalentes: tienen dos subtipos de los virus de Influenza A y un virus B.

- Vacunas Tetravalentes: tienen dos subtipos de los virus A y los dos linajes de virus B: Yamagata y 
Victoria. Desde el 2015, se dispone para el hemisferio Sur de vacunas tetravalentes, se espera que ofrezcan una protección más amplia frente a las infecciones por virus de influenza tipo B.

- En adultos sanos, la vacunación antigripal es protectora. Eficacia $89-90 \%$, incluso cuando los virus circulantes no coinciden exactamente con los virus vacunales.

- En los niños, la eficacia vacunal se incrementa en la primera dosis de $70-80 \%$ y con la segunda dosis a $89-90 \%$.

- En adulto mayor, la vacunación puede ser menos eficaz para prevenir la enfermedad, pero reduce la gravedad de la enfermedad y la incidencia de complicaciones y muertes.

\section{Recomendaciones OMS}

La OMS recomienda la vacunación anual en embarazadas en cualquier fase de la gestación, obesidad mórbida, niños de seis meses a cinco años, adultos mayores de 65 años, pacientes con enfermedades médicas crónicas, profesionales de la Salud.

Ciento ocho países (56\%) han introducido, hasta abril de 2018, la vacunación contra la influenza, 85 países (44\%) no la han introducido. ${ }^{6}$

\section{Razones para la vacunación de influenza en pediatría}

Disminuir la carga de la enfermedad en niños sanos y con condiciones crónicas subyacentes; disminuir las hospitalizaciones asociadas a la influenza y sus complicaciones, incluso la muerte; disminuir la transmisión a los contactos en el hogar y la comunidad, incluyendo las personas con condiciones de alto riesgo, lactantes y adultos mayores y el ausentismo; disminuir la diseminación del virus; inmunidad de «rebaño».7

\section{ACTUALIDADES DE LAS VACUNAS DE INFLUENZA}

Durante muchos años, las vacunas contra la influenza fueron diseñadas para proteger contra tres virus diferentes de la influenza (vacunas trivalentes). Las vacunas trivalentes incluyen un virus de la influenza $A(H 1 N 1)$, un virus de la influenza $A(H 3 N 2)$ y un virus de la influenza $B$. Los expertos debieron elegir un solo virus $B$, a pesar de haber dos líneas diferentes de virus $B$ y que ambos están en circulación durante la mayoría de las temporadas. El hecho de incorporar otro virus B a la vacuna pretende brindar mayor protección contra los virus de la influenza en circulación.

La mayoría de las vacunas contra la influenza en los Estados Unidos ahora son tetravalentes. De los 162 a 169 millones de dosis de vacunas contra la influenza que se calculan para la temporada 2019-2020, los fabricantes estiman que 129 a 138 millones de dosis serán vacunas contra la influenza tetravalentes.

Las vacunas contra la influenza que brindan protección contra cuatro virus de la influenza tienen un perfil de seguridad similar al de las vacunas contra la influenza estacional creadas para proteger contra tres virus, con efectos secundarios similares, en su mayoría leves. Como todas las vacunas contra la influenza estacional, las vacunas que protegen contra cuatro virus de influenza son monitoreadas todos los años para garantizar su seguridad y efectividad.

La vacuna tetravalente no puede causar influenza porque los virus que se usaron para fabricarla están "inactivados" (muertos) o atenuados (debilitados), o los componentes de virus de la influenza con los que están hechas utilizan métodos recombinantes en vez de virus.

Durante la temporada de influenza 2019-2020, los proveedores pueden optar por administrar cualquier vacuna contra la influenza que esté aprobada y que sea adecuada para la edad del paciente (IIV, RIV4 o LAIV4).

Las opciones de esta temporada incluyen:

- Vacunas inyectables contra la influenza en dosis estándar. Como todas las vacunas inactivadas contra la influenza, estas se administran de forma intramuscular. Se suelen administrar con una aguja, pero una (Afluria Quadrivalent) puede aplicarse a ciertas personas (de 18 a 64 años de edad) con una inyección a presión.

- Vacunas inyectables de dosis altas para personas de 65 años de edad en adelante.

- Vacunas hechas con coadyuvantes para personas de 65 años de edad en adelante.

- Vacunas inyectables elaboradas con virus que crecen en cultivo celular. No se utilizaron huevos para la producción de esta vacuna.

- Vacunas inyectables obtenidas a partir de una tecnología de producción de vacunas (vacuna recombinante) que no requiere el uso del virus de la influenza. 


\section{Tabla 1: Vacunas contra la influenza: temporada de influenza 2019-2020.*}

\begin{tabular}{|c|c|c|c|c|c|}
\hline Nombre comercial (fabricante) & Presentación & Indicación de edad & $\begin{array}{l}\text { HA (IIV y RIV4) o recuento } \\
\text { de virus (LAIV4) para cada } \\
\text { virus de vacuna (por dosis) }\end{array}$ & Ruta & $\begin{array}{c}\text { Mercurio (de } \\
\text { timerosal) } \\
(\mu \mathrm{g} / 0.5 \mathrm{~mL})\end{array}$ \\
\hline \multicolumn{6}{|c|}{ IIV4: dosis estándar: a base de huevo ${ }^{\dagger}$} \\
\hline Afluria Quadrivalent (Seqirus) & $\begin{array}{l}\text { PFS de } 0.25 \mathrm{~mL}^{\S} \\
\text { PFS de } 0.5 \mathrm{~mL}^{\S} \\
\text { MDV de } 5.0 \mathrm{~mL}^{\S}\end{array}$ & $\begin{array}{c}6 \text { a } 35 \text { meses } \\
\geq 3 \text { años } \\
\geq 6 \text { meses } \\
\text { (aguja/jeringa) } \\
18 \text { a } 64 \text { años } \\
\text { (inyector de chorro) }\end{array}$ & $\begin{array}{c}7.5 \mu \mathrm{g} / 0.25 \mathrm{~mL}^{\S} \\
15 \mu \mathrm{g} / 0.5 \mathrm{~mL}^{\S}\end{array}$ & $\mathrm{IM}^{\pi}$ & $\begin{array}{c}- \\
- \\
24.5\end{array}$ \\
\hline $\begin{array}{l}\text { Fluarix Quadrivalent } \\
\text { (GlaxoSmithKline) }\end{array}$ & PFS de $0.5 \mathrm{~mL}$ & $\geq 6$ meses & $15 \mu \mathrm{g} / 0.5 \mathrm{~mL}$ & $\mathrm{IM}^{\pi}$ & - \\
\hline $\begin{array}{l}\text { FluLaval Quadrivalent } \\
\text { (GlaxoSmithKline) }\end{array}$ & $\begin{array}{l}\text { PFS de } 0.5 \mathrm{~mL} \\
\text { MDV de } 5.0 \mathrm{~mL}\end{array}$ & $\begin{array}{l}\geq 6 \text { meses } \\
\geq 6 \text { meses }\end{array}$ & $15 \mu \mathrm{g} / 0.5 \mathrm{~mL}$ & $\mathrm{IM}^{\pi}$ & $<25$ \\
\hline $\begin{array}{l}\text { Fluzone Quadrivalent } \\
\text { (Sanofi Pasteur) }\end{array}$ & $\begin{array}{l}\text { PFS de } 0.25 \mathrm{~mL}^{* *} \\
0.5 \mathrm{~mL} \mathrm{PFS}^{* *} \\
0.5 \mathrm{~mL} \text { de } \mathrm{SDV}^{* *} \\
\text { MDV de } 5.0 \mathrm{~mL}^{* *}\end{array}$ & $\begin{array}{c}6 \text { a } 35 \text { meses } \\
\geq 6 \text { meses } \\
\geq 6 \text { meses } \\
\geq 6 \text { meses }\end{array}$ & $\begin{array}{c}7.5 \mu \mathrm{g} / 0.25 \mathrm{~mL}^{* *} \\
15 \mu \mathrm{g} / 0.5 \mathrm{~mL}^{* *}\end{array}$ & $\mathrm{IM}^{\pi}$ & $\begin{array}{l}- \\
- \\
- \\
25\end{array}$ \\
\hline \multicolumn{6}{|c|}{ IIV4: dosis estándar: basada en cultivo celular (ccIIV4) } \\
\hline $\begin{array}{l}\text { Flucelvax Quadrivalent } \\
\text { (Seqirus) }\end{array}$ & $\begin{array}{l}\text { PFS de } 0.5 \mathrm{~mL} \\
\text { MDV de } 5.0 \mathrm{~mL}\end{array}$ & $\begin{array}{l}\geq 4 \text { años } \\
\geq 4 \text { años }\end{array}$ & $15 \mu \mathrm{g} / 0.5 \mathrm{~mL}$ & $\mathrm{IM}^{\pi}$ & $\overline{-}$ \\
\hline \multicolumn{6}{|c|}{ IIV3: dosis alta: a base de huevo† (HD-IIV3) } \\
\hline $\begin{array}{l}\text { Fluzone High-Dose } \\
\text { (Sanofi Pasteur) } \\
\text { IIV3: dosis estándar: a base c }\end{array}$ & $\begin{array}{c}\text { PFS de } 0.5 \mathrm{~mL} \\
\text { huevo }{ }^{\dagger} \text { con adyuvante }\end{array}$ & $\begin{array}{l}\quad \geq 65 \text { años } \\
59 \text { (allV3) }\end{array}$ & $60 \mu \mathrm{g} / 0.5 \mathrm{~mL}$ & $\mathrm{IM}^{\pi}$ & - \\
\hline $\begin{array}{l}\text { Fluad (Seqirus) } \\
\text { RIV4: HA recombinante }\end{array}$ & PFS de $0.5 \mathrm{~mL}$ & $\geq 65$ años & $15 \mu \mathrm{g} / 0.5 \mathrm{~mL}$ & $\mathrm{IM}^{\pi}$ & - \\
\hline $\begin{array}{l}\text { Flublok Quadrivalent } \\
\text { (Sanofi Pasteur) } \\
\text { LAIV4: a base de huevo }^{\dagger}\end{array}$ & PFS de $0.5 \mathrm{~mL}$ & $\geq 18$ años & $45 \mu \mathrm{g} / 0.5 \mathrm{~mL}$ & $\mathrm{IM}^{\pi}$ & - \\
\hline $\begin{array}{l}\text { FluMist Quadrivalent } \\
\text { (AstraZeneca) }\end{array}$ & $\begin{array}{l}\text { Pulverizador intra- } \\
\text { nasal de un solo uso } \\
\text { precargado de } 0.2 \mathrm{~mL}\end{array}$ & 2 a 49 años & $\begin{array}{l}10^{6.5-7.5} \text { unidades de foco } \\
\text { fluorescente/ } 0.2 \mathrm{~mL}\end{array}$ & NAS & - \\
\hline
\end{tabular}

Abreviaturas: ACIP = Comité Asesor sobre Prácticas de Inmunización; FDA = Administración de Alimentos y Medicamentos; HA = hemaglutinina; IIV3 = vacuna inactivada contra la gripe, trivalente; IIV4 = vacuna antigripal inactivada, cuadrivalente, IM = intramuscular; LAIV4 = vacuna viva atenuada contra la influenza, cuadrivalente; MDV = vial multidosis; NAS = intranasal; PFS = jeringa precargada; RIV4 = vacuna recombinante contra la gripe, cuadrivalente; SDV = vial de dosis única. * Los proveedores de vacunas deben consultar la información de prescripción aprobada por la FDA para las vacunas contra la gripe 2019-2020 para obtener la información más completa y actualizada, incluyendo (pero sin limitarse a) indicaciones, contraindicaciones, advertencias y precauciones. Los prospectos de las vacunas autorizadas en los Estados Unidos están disponibles en el ícono https:/www.fda.gov/vaccines-blood-biologics/approved-products/vaccines-licensed-use-united-statesexternal. La disponibilidad de productos y presentaciones específicos podría cambiar y diferir de lo que se describe en este cuadro y en el texto del presente informe.

† Las personas con antecedentes de alergia al huevo pueden recibir cualquier vacuna autorizada y recomendada contra la gripe que, por lo demás, sea apropiada para su edad y estado de salud. Aquellas personas que informen haber tenido reacciones al huevo que impliquen síntomas distintos de la urticaria (por ejemplo, angioedema o hinchazón, dificultad respiratoria, mareos o emesis recurrentes) o que hayan requerido epinefrina u otra intervención médica de emergencia deben ser vacunadas en un entorno médico de hospitalización o ambulatorio (incluyendo, pero no limitándose, a hospitales, clínicas, departamentos de salud y consultorios médicos). La administración de la vacuna debe ser supervisada por un proveedor de atención de la salud que sea capaz de reconocer y manejar las reacciones alérgicas graves. $\S$ El volumen de la dosis de Afluria Cuadrivalente es de $0.25 \mathrm{~mL}$ para niños de 6 a 35 meses y de $0.5 \mathrm{~mL}$ para personas de $\geq 3$ años.

"Las vacunas contra la gripe de administración intramuscular deben administrarse únicamente con aguja y jeringa, con la excepción de la presentación en forma de MDV de Afluria Quadrivalent, que puede administrarse alternativamente con el inyector de chorro PharmaJet Stratis para personas de 18 a 64 años de edad únicamente. En el caso de los adultos y los niños mayores, el sitio recomendado para la vacunación antigripal IM es el músculo deltoides. El sitio preferido para los lactantes y los niños pequeños es el aspecto anterolateral del muslo. En las Directrices Generales de Mejores Prácticas de Inmunización del ACIP (ícono https:// www.cdc.gov/vaccines/hcp/acip-recs/general-recs/downloads/general-recs.pdfpdf) se ofrece orientación adicional sobre la selección del sitio y la longitud de la aguja para la administración intramuscular.

** El Cuadrivalente de Fluzona puede administrarse a niños de 6 a 35 meses de edad ya sea como $0.25 \mathrm{~mL}$ por dosis $00.5 \mathrm{~mL}$ por dosis. No se expresa ninguna preferencia por uno u otro volumen de dosis para este grupo de edad. Las personas de 3 años deben recibir el volumen de la dosis de $0.5 \mathrm{~mL} .^{10}$ 


\section{- La vacuna contra la influenza con virus vivos} atenuados (LAIV). Una vacuna hecha con virus vivos atenuados que se administra con atomizador nasal. ${ }^{8}$

El cuadrivalente de dosis alta Fluzone de Sanofi (vacuna contra la influenza) ha obtenido la aprobación de la Administración de Drogas y Alimentos de los Estados Unidos (FDA) para su uso en adultos, mayores de 65 años.

Fluzone High-Dose (vacuna contra la influenza) fue aprobada como una vacuna trivalente contra la influenza por el regulador de los EE.UU. en 2009, que cubrió las dos cepas de influenza A y una cepa de influenza $B$.

La formulación cuadrivalente de la vacuna, que ahora ha sido aprobada para personas mayores, contiene una cepa adicional de influenza B. Después de la aprobación de su solicitud de licencia de productos biológicos suplementarios, Fluzone Quadrivalent High-Dose se puede usar para proteger a las personas mayores de la enfermedad de influenza causada por las cepas de influenza A y B presentes en la vacuna (Tabla 1). El ensayo de etapa tardía vio a Fluzone Quadrivalent de alta dosis alcanzar el punto final primario de inmunogenicidad no inferior. Esto fue en comparación con dos formulaciones trivalentes de Fluzone High-Dose con cada una de las dos cepas de influenza $B$ recomendadas para ser incluidas en la vacuna para la temporada de influenza 2017-2018.

En un criterio de valoración secundario del ensayo de fase 3 , cada cepa $B$ en la formulación cuadrivalente de la vacuna desencadenó una respuesta inmune superior, en comparación con la formulación trivalente que no tenía la cepa B correspondiente. ${ }^{9}$

En octubre de 2018, la FDA aprobó una indicación de edad ampliada para Afluria Quadrivalent (IIV4). Con licencia previa para personas de $\geq 5$ años (Tabla 1), Afluria Quadrivalent (IIV4) ahora tiene licencia para personas de $\geq 6$ meses. El volumen de dosis es de $0.25 \mathrm{~mL}$ por dosis (que contiene $7.5 \mu \mathrm{g}$ de HA por virus de la vacuna) para niños de seis años de edad a través de 35 meses y $0.5 \mathrm{~mL}$ por dosis (que contienen $15 \mu \mathrm{g}$ de HA por virus de la vacuna) para todas las personas de $\geq 36$ meses ( $\geq 3$ años). ${ }^{10}$

Un IIV o RIV4 (según sea apropiado para la edad del receptor) es adecuado para personas en todos los grupos de riesgo. LAIV4 no se recomienda para algunas poblaciones, incluidos algunos de estos grupos enumerados. Se observan contraindicaciones

\begin{tabular}{|c|c|}
\hline Medicación (oseltamivir) & $\begin{array}{c}\text { Tratamiento (dosis } 2 \text { veces al } \\
\text { día) por } 5 \text { días }\end{array}$ \\
\hline Adultos & $75 \mathrm{mg}$ \\
\hline \multicolumn{2}{|l|}{ Niños > de 12 meses } \\
\hline $15 k$ & $30 \mathrm{mg}$ \\
\hline$>15-23 k$ & $45 \mathrm{mg}$ \\
\hline$>23-40 \mathrm{k}$ & $60 \mathrm{mg}$ \\
\hline$>40 \mathrm{k}$ & $75 \mathrm{mg}$ \\
\hline Lactantes de 9 a $11 \mathrm{~m}$ & $3.5 \mathrm{mg} / \mathrm{k}$ \\
\hline A término de 0 a $8 \mathrm{~m}$ & $3 \mathrm{mg} / \mathrm{k}$ \\
\hline Pretérmino* & \\
\hline
\end{tabular}

y precauciones para el uso de LAIV4: Las personas que están inmunocomprometidas por cualquier causa (incluidas, entre otras, la inmunosupresión causada por medicamentos o infección por VIH).

- Mujeres que están o estarán embarazadas durante la temporada de influenza.

- Niños y adolescentes (de seis meses a 18 años) que reciben medicamentos que contienen aspirina o salicilato y que podrían estar en riesgo de experimentar el síndrome de Reye después de la infección por el virus de la influenza.

- Residentes de hogares de ancianos y otros centros de atención a largo plazo.

- Indios americanos/nativos de Alaska.

- Personas extremadamente obesas (índice de masa corporal $\geq 40$ para adultos).

\section{TRATAMIENTO}

Pacientes con influenza estacional no complicada: los pacientes sin riesgo: tratamiento sintomático. Reposo y en casa para reducir el riesgo de transmisión. Manejo de fiebre. Signos de alarma ante deterioro clínico.

Los grupos con alto riesgo de padecer enfermedad grave o complicaciones: antivirales.

Pacientes con influenza estacional Grave o Progresiva: síndrome neumónico, septicemia o exacerbación de enfermedades crónicas. Dar antivirales lo antes posible. Los Inhibidores de la neuraminidasa, como el oseltamivir (Tablas $2 y$ 3), en las 48 horas siguientes a la aparición de los síntomas. Se recomienda tratamiento mínimo cinco 
días, ampliables hasta mejoría clínica. Los virus influenza circulantes son resistentes a los antivirales amantadina y rimantidina, por lo que no se recomiendan como monoterapia.

Los médicos pueden considerar el tratamiento antiviral para adultos y niños que no tienen un alto riesgo de complicaciones de la influenza, con influenza documentada o sospechada, independientemente de la historia de vacunación contra la influenza, que son:

- Pacientes ambulatorios con inicio de enfermedad $\leq 2$ días antes de la presentación.

- Pacientes ambulatorios sintomáticos que son contactos en el hogar de personas que corren un alto riesgo de desarrollar complicaciones por la influenza, particularmente aquéllos que están gravemente inmunocomprometidos.

- Proveedores de atención medica sintomáticos que atienden a pacientes con alto riesgo de desarrollar complicaciones por la influenza, particularmente aquéllos que están gravemente inmunocomprometidos. ${ }^{5,11}$

El fosfato de oseltamivir oral ha sido aprobado por la FDA para el tratamiento de la influenza grave, pero sin complicaciones dentro de los dos días de la aparición de la enfermedad en personas de 14 días de vida en adelante y para la quimioprofilaxis en personas de un año de edad en adelante. Si bien el uso de oseltamivir oral para el tratamiento de la influenza en bebés con menos de 14 días de vida y para la quimioprofilaxis en bebés de tres meses a un año no forma parte de las indicaciones aprobadas por la FDA, es recomendado por los CDC y la American Academy of Pediatrics. Si el niño tiene menos de tres meses, no se recomienda el uso de oseltamivir para la quimioprofilaxis a menos que se considere que la situación es crítica debido a los datos limitados que existen para este grupo etario.

Tabla 3: Dosificación para niños que pesan menos de 40 kg.

\begin{tabular}{ccc} 
& & $\begin{array}{c}\text { Cantidad de mezcla de } \\
\text { antiviral }(1 \mathrm{~mL}=15 \mathrm{mg}) \\
\mathrm{mL}(\mathrm{mg})\end{array}$ \\
\hline Peso (kg) & Edad (años) & $2(30)$ \\
$\leq 15$ & $1-2$ & $3(45)$ \\
15 a 23 & $3-5$ & $4(60)$ \\
23 a 40 & $6-9$ &
\end{tabular}

Autolesión o delirio, reportados principalmente entre pacientes pediátricos japoneses.

El zanamivir para inhalar está aprobado por la FDA para el tratamiento de la influenza grave pero sin complicaciones dentro de los dos días de la aparición de la enfermedad en personas de siete años en adelante, y para la quimioprofilaxis de la influenza en personas de cinco años en adelante. Está contraindicado el uso del zanamivir para inhalar en pacientes con historial clínico de alergia a las proteínas de la leche.

El peramivir intravenoso está aprobado por la FDA para el tratamiento de la influenza grave pero sin complicaciones dentro de los dos días de la aparición de la enfermedad en personas de dos años de edad en adelante. La efectividad del peramivir se determina de acuerdo con las pruebas clínicas en oposición al placebo en las que el tipo de virus predominante era el virus de la influenza $A$.

No hay datos para el uso del peramivir o baloxavir para la quimioprofilaxis de influenza.

El baloxavir marboxil oral está aprobado por la FDA para el tratamiento de la influenza grave pero sin complicaciones dentro de los dos días de la aparición de la enfermedad en personas de 12 años de edad en adelante que están sanas o tienen alto riesgo de desarrollar complicaciones relacionadas con la influenza. Se ha establecido la seguridad y eficacia del baloxavir para el tratamiento de la influenza en pacientes pediátricos de 12 años de edad en adelante que pesan al menos $40 \mathrm{~kg}$. No se ha determinado la seguridad y eficacia en pacientes $<12$ años de edad o que pesan menos de $40 \mathrm{~kg}$. La eficacia del baloxavir para la aprobación inicial de la FDA en octubre del 2018 se determinó según ensayos clínicos en pacientes ambulatorios de 12 a 64 años que anteriormente estaban sanos (Hayden, 2018). ${ }^{12}$ El tratamiento con baloxavir de dosis única fue superior al de placebo y tuvo una eficacia clínica similar en el tiempo del alivio de los síntomas que un tratamiento de cinco días con oseltamivir. En octubre del 2019, la FDA aprobó una indicación para el tratamiento con baloxavir de casos de influenza graves pero sin complicaciones dentro de los dos días de la aparición de la enfermedad en personas de 12 años de edad en adelante con alto riesgo de tener complicaciones relacionadas con la influenza, con base en los resultados de un ensayo clínico (Ison, 2018; Baloxavir marboxil (Xofluza) Sitio web de la Administración de Alimentos y Medicamentos de EE.UU. 2019) En este ensayo clínico de la iniciación 
temprana del tratamiento antiviral de la influenza sin complicaciones en pacientes con alto riesgo, el baloxavir fue superior al placebo y tuvo una eficacia similar al oseltamivir en cuanto al tiempo transcurrido para el alivio de los síntomas. En el caso de los pacientes con infección por virus de influenza $\mathrm{B}$, el baloxavir redujo considerablemente el tiempo promedio para mejorar los síntomas en comparación con el oseltamivir, por más de 24 horas. No obstante, no hay datos disponibles sobre el tratamiento de la influenza con baloxavir en mujeres embarazadas, personas inmunodeprimidas o personas con influenza grave. No hay datos disponibles de ensayos clínicos sobre el tratamiento con baloxavir de pacientes hospitalizados con influenza. ${ }^{11}$

\section{REFERENCIAS}

1. Center for Diseases Control and Prevention (CDC) [Internet]. 2018 [actualizado 10 julio 2019; citado 28 enero de 2020]. Disponible en: https://www.cdc.gov/flu/index.htm

2. Reproduced and adapted with permission of Dr Masato Tashiro, Director, Center for Influenza Virus Research, National Institute of Infectious Diseases [internet] 2009 (NIID) Japan. [citado 28 de enero de 2020] Disponible en: https://www.niid.go.jp/niid/en/flu-e.html

3. Weekly /Influenza Report EW 3/Regional Update: Influenza $\&$ Others Respiratory Viruses. PAHO/OPS influenza regional update [internet] 28 de enero de 2020 [citado el 03 de febrero 2020] Disponible en: https://www.paho.org/hq/index. php?option=com_docman\&view=download\&category slug=see-influenza-reports-by-year-4302\&alias $=51471$ regional-update-influenza-epidemiological-week-3-january28-2020\&ltemid=270\&lang=en

4. Influenza Global Update 358 Based on data up to December 22 , 2019. [Internet] [actualizado 06 de enero de 2020; citado 28 de enero 2020]. Disponible en: https://www.who.int/ influenza/surveillance_monitoring/updates/2020_01_06_ surveillance_update_358.pdf?ua=1

5. World Health Association. Influenza [Internet] [actualizado 6 de noviembre 2018; citado 28 de enero 2020]. Disponible en: https://www.who.int/news-room/fact-sheets/detail/ influenza-(seasonal)
6. WHO/IVB Database, Map production Immunization Vaccines and Biologicals (IVB), World Health Organization. [Internet] Department of Immunization, Vaccine and Biologicals (Geneva 27, Switzerland); 2017 [actualizado 13 de junio 2017; citado 28 de enero 2020]. Disponible en: https:// extranet.who.int/ivb_docs/reports/catalogue

7. Committee on Infectious Diseases. Recommendations for Prevention and Control of Influenza in Children, 2017-2018. Pediatrics [Internet]. 2017 [citado 28 de enero 2020]; 140 (4): 10-18. Disponible en: https://pediatrics.aappublications. org/content/pediatrics/140/4/e20172550.full.pdf

8. Flumaraton [Internet]. Londres: Editado por el redactor del personal de PBR; 2019 [actualizado 5 de noviembre 2019; citado 28 de enero 2020]. Disponible en: https://www. flumaraton.com/post/la-fda-aprueba-nueva-formula-defluzone-de-sanofi-en-personas-mayores.

9. Center for Diseases Control and Prevention (CDC) [Internet]. 2020 [actualizado 17 enero 2020; citado 02 febrero de 2020]. Disponible en: https://espanol.cdc.gov/enes/flu/season/faqflu-season-2019 / 2020.htm\#anchor_1568639330820

10. Grohskopf LA, Alyanak E, Broder KR, Walter EB, Fry AM, Jernigan DB. Prevención y control de la influenza estacional con vacunas: recomendaciones del Comité Asesor sobre Prácticas de Inmunización - Estados Unidos, temporada de influenza 2019-20. MMWR [Internet]. 2019 [citado 02 febrero de 2020]; 68 (3): 1-21. Disponible en: https://www. ncbi.nlm.nih.gov/pmc/articles/PMC6713402/

11. Uyeki TM, Bernstein HH, Bradley JS, Englund JA, File TM, Fry AM. Guías de práctica clínica de la Sociedad de Enfermedades Infecciosas de América: Actualización de 2018 sobre diagnóstico, tratamiento, quimioprofilaxis y manejo de brotes institucionales de la influenza estacional. Clin Infect Dis [Internet]. 2019 [citado 02 febrero de 2020]; 68 (6): 895-902. Disponible en: https://www.ncbi.nlm.nih. gov/pmc/articles/PMC6769232/

12. Hayden FG, Sugaya N, Hirotsu N, Lee N, Jong MD, Hurt $A C$ et al. Baloxavir marboxil for uncomplicated influenza in adults and adolescents. N Engl J Med. 2018; 379: 913-923.
Correspondencia:
Pio López
Calle 5B5 \#37 bis-20,
Cali, Colombia.
E-mail: pio.lopez@ ceiponline.org 